\title{
Domperidone-Associated Sudden Cardiac Death in the General Population and Implications for Use in Patients Undergoing Hemodialysis: A Literature Review
}

\author{
Joy Makari, Karen Cameron, and Marisa Battistella
}

\begin{abstract}
Background: Domperidone, an effective prokinetic agent, is commonly used to manage symptoms of gastroparesis. Health regulatory agencies have issued warnings about an increased risk of sudden cardiac death associated with use of this drug.

Objective: To evaluate the evidence for domperidone-associated sudden cardiac death and to determine whether this drug can be safely used for gastroparesis in patients undergoing dialysis.

Data Sources: Two databases (MEDLINE [1965 to September 2014] and Embase [1980 to September 2014]) were searched using the Medical Subject Headings "domperidone", "sudden cardiac death", and "cardiac arrhythmia". The search was limited to studies conducted in humans and published in English. Advisories from health regulatory agencies (Health Canada, the European Medicines Agency, and the US Food and Drug Administration) were identified and reviewed.
\end{abstract}

Study Selection: Studies eligible for inclusion in this narrative review were randomized controlled trials and cohort, case-control, crosssectional, and other epidemiological studies comparing use and non-use of domperidone for the outcome of sudden cardiac death in adults. Abstracts of eligible case reports and case series were also included.

Data Synthesis: Despite inconsistencies in their decisions, the various drug regulatory authorities have acknowledged the potential safety concern of increased risk of sudden cardiac death associated with domperidone. To date, no randomized controlled studies have shown an increased risk of this outcome secondary to domperidone use. Current regulatory recommendations and approval decisions are based on 2 large observational epidemiological studies that generated a signal of increased risk. The strengths and limitations of these studies were evaluated in detail. No direct evidence applicable to patients with end-stage renal disease was found. In vitro evidence suggests that the risk of sudden cardiac death is dose-related.

Conclusions: Given gaps in the literature, use of domperidone for patients undergoing dialysis should be assessed on a case-by-case basis. Extreme caution should be used for patients taking more than $30 \mathrm{mg} / \mathrm{day}$ of this drug.

Keywords: domperidone, sudden cardiac death, cardiac arrhythmia, dialysis

\section{RÉSUMÉ}

Contexte : La dompéridone, un agent procinétique efficace, est couramment utilisée pour traiter les symptômes de la gastroparésie. Les organismes de réglementation en santé ont émis des mises en garde à propos du risque accru de mort subite d'origine cardiaque associée à l'utilisation de ce médicament.

Objectif : Évaluer les données probantes portant sur la mort subite cardiaque associée à la dompéridone et déterminer si ce médicament peut être utilisé en toute sécurité pour traiter les patients sous dialyse atteints de gastroparésie.

Sources des données : Deux bases de données (MEDLINE [1965 à septembre 2014] et Embase [1980 à septembre 2014]) ont été interrogées en utilisant les mots clés des Medical Subject Headings suivants : " domperidone " (dompéridone), " sudden cardiac death " (mort subite cardiaque) et " cardiac arrhythmia " (arythmie cardiaque). La recherche se limitait aux études effectuées chez l'humain et publiées en anglais. Les avis émis par les organismes de réglementation en santé (Santé Canada, l'Agence européenne des médicaments et la Food and Drug Administration des États-Unis) ont été relevés et examinés.

Sélection des études: Les études admissibles à cette analyse narrative étaient les essais cliniques à répartition aléatoire, les études de cohorte et cas-témoins, les études transversales et autres études épidémiologiques dans lesquelles étaient comparées l'utilisation et la non-utilisation de la dompéridone quant à la mort subite cardiaque chez les adultes. Les résumés des études de cas et des séries de cas admissibles ont aussi été inclus.

Synthèse des données : Malgré des divergences dans leurs décisions, les différents organismes de réglementation des médicaments reconnaissent qu'un risque accru de mort subite cardiaque soit un éventuel problème de sécurité associé à l'utilisation de la dompéridone. À ce jour, aucun essai clinique à répartition aléatoire n'a montré qu'une augmentation du risque de cet effet est secondaire à l'administration de la dompéridone. Les recommandations réglementaires actuelles et les décisions en matière d'approbation sont fondées sur deux importantes études épidémiologiques d'observation qui ont sonné l'alarme à propos d'une augmentation du risque. Les forces et les faiblesses de ces études ont été examinées en détail. Il n'y a pas de preuve directe applicable à la population atteinte d'insuffisance rénale terminale. D'après les données in vitro, le risque de mort subite cardiaque est lié à la dose administrée. 


\section{Can J Hosp Pharm. 2014;67(6):441-6}

Conclusions : Étant donné les lacunes dans la littérature, il est recommandé que l'utilisation de dompéridone chez les patients sous dialyse soit évaluée au cas par cas. Il faut faire preuve d'énormément de prudence chez les patients qui prennent quotidiennement plus de $30 \mathrm{mg}$ de ce médicament.

Mots clés : dompéridone, mort subite cardiaque, arythmie cardiaque, dialyse

[Treduction par l'éditeur]

\section{INTRODUCTION}

$\mathrm{I}^{\mathrm{n}}$ the general population of the United States, the incidence of sudden cardiac death (SCD) ranges from 180000 to 450000 per year. ${ }^{1} \mathrm{SCD}$ is devastating because of its unexpected nature and multifactorial etiology. It is most often caused by an interplay of risk factors causing a structural abnormality in the heart and a transient trigger (e.g., medication, electrolyte abnormality) that induces an electrophysiological imbalance. ${ }^{1}$ This interaction can predispose individuals to prolongation of the QTc interval, which represents an altered frequency of ventricular repolarization. ${ }^{2}$ Ultimately, these electrophysiological changes can lead to fatal ventricular tachyarrhythmia and eventual hemodynamic collapse. ${ }^{1}$

The risk factors for SCD include pre-existing coronary artery disease, heart failure, left ventricular hypertrophy, and diabetes mellitus. ${ }^{1}$ End-stage renal disease heightens the risk of SCD about 2.5-fold because of chronic hemodynamic overload and inflammatory stress, remodelling of the heart muscle, vascular calcification, and dialysis itself, which can result in rapid electrolyte shifts, hypotension, and myocardial ischemia. ${ }^{1}$ In a recent study, about $50 \%$ of patients undergoing dialysis had a prolonged QTc interval (> $440 \mathrm{~ms}) .{ }^{2}$ Overall, cardiovascular disease is the primary cause of death in patients with end-stage renal disease, and SCD accounts for $60 \%$ of these cases. ${ }^{2}$

The clinical dilemma of how to manage a patient who needs a drug that will potentially prolong the QTc interval often involves weighing the benefits and risks to the patient. One common example is that of domperidone for the treatment of gastroparesis. Diabetes accounts for $45 \%$ of patients starting

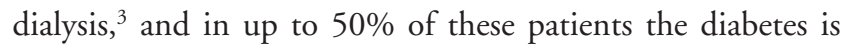
complicated by gastroparesis. ${ }^{4}$ Prokinetic agents, such as domperidone and metoclopramide, are commonly used for relief of symptoms. ${ }^{5}$ Domperidone and metoclopramide are equally efficacious. ${ }^{5}$ Unlike metoclopramide, however, domperidone does not appear to cause extrapyramidal side effects (e.g., restlessness, akathisia, acute dystonia) because of its poor penetration of the blood-brain barrier. ${ }^{5}$ Given the more favourable side effect profile, many clinicians in European countries and in Canada prefer domperidone as a first-line agent. ${ }^{4}$

Despite these advantages, domperidone is associated with cardiovascular concerns. Health Canada,${ }^{6}$ the European
Medicines Agency, ${ }^{7}$ and the US Food and Drug Administration ${ }^{8}$ have issued advisory warnings to inform health care professionals of an associated increase in the risk of SCD among patients over the age of 60 years who are taking more than $30 \mathrm{mg}$ of domperidone daily. Health Canada has additionally stipulated that extra caution should be exercised in patients with predisposing risk factors for cardiac arrhythmias. ${ }^{6}$ The clinical questions posed for this study were the following: To what degree are these warnings supported by the literature, and how should clinicians weigh the benefits and risks of using domperidone in patients with predisposing risk factors for cardiac arrhythmias? This review aimed to evaluate and discuss the evidence that supports these warnings for the general population and to consider the implications for patients undergoing hemodialysis. No specific literature is available on the risk of SCD due to domperidone use among adults requiring hemodialysis, so clinicians may gauge the risk by extrapolating knowledge and experience from other populations.

\section{METHODS}

A literature search was performed for the purpose of composing a narrative review. Two databases (MEDLINE [1965 to September 2014] and Embase [1980 to September 2014]) were searched using the MeSH (Medical Subject Heading) terms "domperidone" AND "sudden cardiac death" OR "cardiac arrhythmia". The MeSH terms were exploded to include all subheadings. The search was limited to studies conducted in humans and published in English. Published advisories from health regulatory agencies (Health Canada, the European Medicines Agency, and the US Food and Drug Administration) were identified and reviewed. Titles and abstracts were reviewed against the inclusion criteria. Studies selected for full-text review were randomized controlled trials, cohort studies, case-control studies, cross-sectional studies, and other epidemiological studies comparing use and non-use of domperidone for the outcome of SCD in adults 18 years of age and older. Also eligible for inclusion were abstracts of case reports or case series involving adults 18 years of age or older and comparing use and non-use of domperidone for the outcomes of QTc prolongation or SCD. Review articles and animal studies were excluded. 


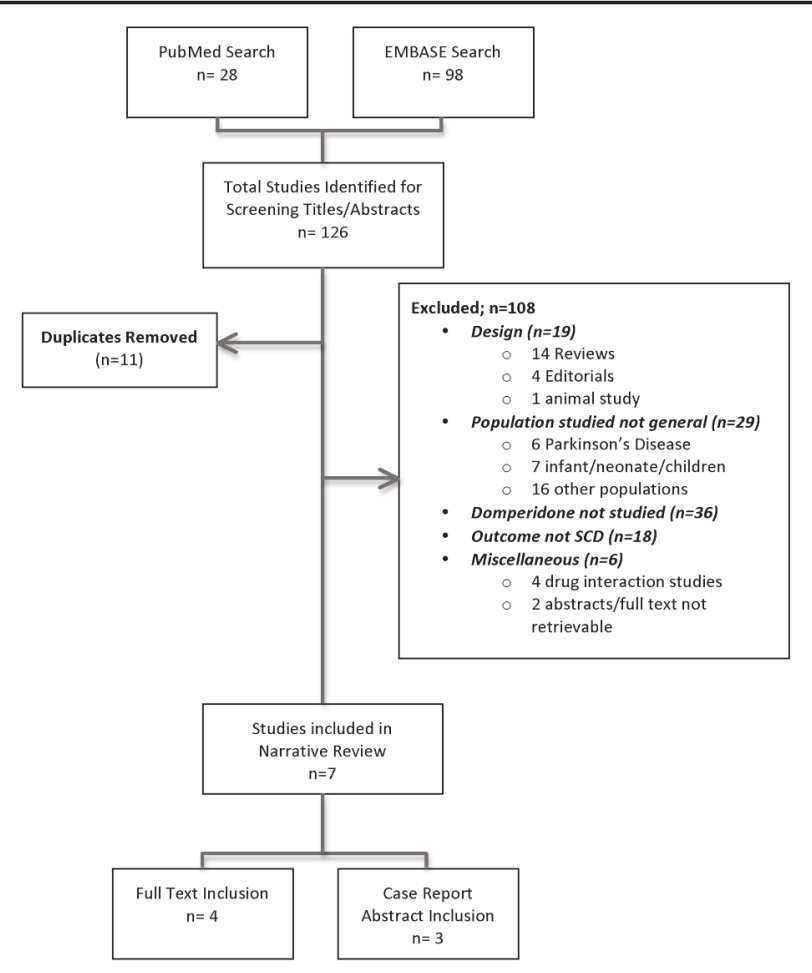

Figure 1. Flow diagram for studies included in a narrative review of domperidone-associated sudden cardiac death (SCD).

\section{RESULTS}

The database searches yielded a total of 126 citations, 28 from MEDLINE and 98 from Embase. Of these, 11 were duplicates, and an additional 108 studies did not meet the inclusion criteria because of study design, study population, intervention drug other than domperidone (e.g., methadone, serotonin reuptake inhibitors), outcomes other than SCD, or other reasons (Figure 1). Overall, 7 studies were retained for this narrative review: 4 studies with full-text review and 3 case reports with review of abstracts only.

There was a paucity of evidence to support warnings of an increased risk of SCD due to domperidone use. Review of the literature for humans cited as supporting the advisories from health regulatory agencies ${ }^{6-8}$ showed that these advisories are based primarily on 2 observational epidemiological studies evaluating data derived from public health databases in the Netherlands ${ }^{9}$ and the province of Saskatchewan in Canada, ${ }^{10}$ both of which were also identified in the literature search for this narrative review.

Noord and others ${ }^{9}$ conducted a prospective, populationbased case-control study over the period 1996 to 2007 to evaluate the association between use of domperidone and both nonfatal cardiac arrhythmia and SCD in the general population. Data were obtained from a longitudinal database of electronic medical records from general practitioners in the Netherlands for patients aged 18 years or older who did not have cancer. ${ }^{9}$ The report did not explicitly state whether patients undergoing dialysis were excluded. All participants were followed until occurrence of the primary outcome of interest (SCD or arrhythmia). Cases were identified by a sensitive search of narrative reports and codes and were validated by blinded physician review of the medical records. Controls were matched to cases at random on the basis of 4 variables: age, sex, practice site, and index date. Exposure odds ratios (ORs) were determined by conditional logistic regression with adjustment for identified confounders. The authors presented data for a total of 1366 cases and 14114 matched controls. Only 10 cases of SCD among the 1366 cases identified involved current domperidone users, which produced an unadjusted OR for domperidone and SCD of 3.72 (95\% confidence interval [CI] 1.72-8.08). More specifically, when the data were analyzed by daily dosage, doses greater than $30 \mathrm{mg}$ daily were associated with an increased risk of SCD (adjusted OR 11.4, 95\% CI 1.99-65.2). ${ }^{9}$ The authors concluded that current use of domperidone, particularly at high doses, was associated with an increased risk of SCD.

The strengths of the study by Noord and others ${ }^{9}$ included the large study population, the 12-year prospective study period, and an appropriate data collection methodology. However, an important limitation was the high imprecision and uncertainty of the ORs. The adjusted OR of 11.4 was based on an absolute number of only 4 cases of current users of domperidone at doses greater than $30 \mathrm{mg}$ daily matched with only 3 controls. ${ }^{9}$ The small number of cases likely resulted in the high degree of uncertainty, indicated by the wide 95\% CI (1.99-65.2). Furthermore, the association was not observed for patients receiving less than or exactly $30 \mathrm{mg}$ daily: only 2 cases of SCD were identified among those who received less than $30 \mathrm{mg}$ daily and only 4 cases among those who received exactly $30 \mathrm{mg}$ daily. ${ }^{9}$ These small numbers of cases and controls compromise the validity of the authors' conclusion. These values are not persuasive in terms of indicating an overall increase in risk, as there is increased probability that the findings were due to other factors not related to the use of domperidone. Overall, because the increased risk cannot be concluded with certainty, this study is deemed to have generated a safety signal, and its results should be interpreted with care.

Johannes and others ${ }^{10}$ conducted a retrospective, nested casecontrol study with data derived from the linked administrative database of Saskatchewan Health. Patients were included if they had received provincially funded health care and had outpatient drug benefits. The report did not explicitly state whether patients undergoing dialysis were excluded. This nested case-control study examined the combined risk of sudden ventricular arrhythmia and SCD in a 3-way comparison. Outcomes were compared for current users of oral domperidone, current users of proton pump inhibitors (PPIs), and non-users of either medication for the 
period 1990 to 2005. Cases were identified using hospital discharge and vital statistics codes and were validated by blinded cardiologist review of the abstracted hospital charts. Each case was matched to a maximum of 4 controls by diabetes status, sex, age, and index date. The ORs for current domperidone exposure relative to non-use or PPI use were determined by conditional logistic regression with adjustment for identified confounders. A total of 83212 exposed individuals, 1608 cases, and 6428 matched controls were identified. The adjusted ORs were 1.59 (95\% CI 1.28-1.98) for current domperidone use relative to non-use and 1.44 (95\% CI 1.12-1.86) for current domperidone use relative to PPI use. In stratified analyses, the unadjusted OR for current domperidone use relative to non-use was numerically higher for case-control pairs without diabetes, for those older than 60 years, and for men. ${ }^{10}$ The authors acknowledged that the 95\% CIs for some of the stratified point estimates were wide, which reflected the small number of cases in those subgroups; however, the absolute numbers of cases were not specified. Specifically, the study reported a significantly higher risk of SCD among patients over 60 years of age (OR 1.64, 95\% CI 1.31$2.05)$, but the result was nonsignificant among patients 60 years of age or younger (OR 1.10, 95\% CI 0.35-3.37). The authors concluded that current domperidone use increases the risk of SCD.

Similar to the study by Noord and others, ${ }^{9}$ the strengths of the study by Johannes and others ${ }^{10}$ included the large study population, the 15-year study period, and an appropriate data collection methodology. In addition, the 3-way comparison of domperidone use with non-use and PPI use may have strengthened the authors' findings by minimizing bias by indication. Although the estimates provided in this study ${ }^{10}$ were more precise than those in the study by Noord and others, ${ }^{9}$ many uncertainties remain. Johannes and other ${ }^{10}$ acknowledged that multivariate analysis of current domperidone use compared with non-use or PPI use shifted the point estimate toward the null, which suggested that confounders not accounted for might be inflating the OR estimates. ${ }^{10}$ In addition, both studies ${ }^{9,10}$ relied on databases containing information that was recorded for purposes other than the primary outcomes specified by Noord and others ${ }^{9}$ and Johannes and others. ${ }^{10}$ Interestingly, Health Canada used the study by Johannes and others ${ }^{10}$ as support for its recommendation that patients over the age of 60 years should not receive domperidone doses greater than $30 \mathrm{mg}$ daily. However, this recommendation is based on an unadjusted stratified analysis that had a high degree of uncertainty because of the small sample. Furthermore, the study lacked transparency, as the exact numbers of cases and controls in this subgroup were not reported. Finally, the findings of the stratified analysis were inconsistent with previously established risk factors. For example, given that the incidence of cardiac comorbidities tends to be greater among patients with diabetes, one would not expect patients without diabetes to be at greater risk of SCD than those with diabetes, as was shown in this study. ${ }^{10}$

Although not cited in the advisory warnings issued by health regulatory agencies, our search yielded 2 additional relevant studies examining the link between domperidone use and SCD. Jolly and others ${ }^{11}$ conducted a post mortem case-control study in the general population to examine the risk of SCD in relation to use of any non-cardiac QTc-prolonging drug. For a small subset of cases of SCD in domperidone users matched to nonusers ( $n=6$ cases and 12 controls), the adjusted OR was marginally significant, with a wide CI (OR 1.60, 95\% CI 0.564.56). Similarly, Straus and others ${ }^{12}$ conducted a populationbased case-control study examining the risk of SCD associated with any non-cardiac QTc-prolonging drugs, including domperidone. The adjusted OR for 9 cases of SCD in domperidone users matched with 15 controls was 3.8 (95\% CI 1.5-9.7). Although the data suggested a trend toward increased risk of SCD with domperidone use, these 2 studies were also limited by small numbers of cases, wide CIs, and observational designs.

In addition to these studies, QTc prolongation secondary to domperidone use has been described in previous literature, with most of the clinical data derived from neonatal settings. ${ }^{13,14}$ The adult literature is limited to case reports, ${ }^{15-17}$ case-control studies, and case series of cardiotoxicity secondary to IV domperidone, a formulation that is no longer available. ${ }^{18} \mathrm{QTc}$ prolongation secondary to domperidone use has also been demonstrated in animal studies and in vitro models. ${ }^{18}$ Interestingly, one in vitro study showed that both metoclopramide and domperidone bind to and block $h E R G$ (human ether-à-go-gorelated gene) channels in a concentration-dependent manner. ${ }^{19}$ Blockade of the $h E R G$ channel is a likely mechanism for QTc prolongation, and it has been shown that domperidone is a more potent blocker of $h E R G$ currents (by a factor of 100) than metoclopramide; however, this finding has not been confirmed in vivo. ${ }^{19}$

\section{DISCUSSION}

Overall, the clinical evidence for adults suggesting an increased risk of SCD secondary to domperidone use is limited to observational studies, case reports, and case series. These study designs are generally considered to represent low-quality evidence. Although there are no formal guidelines regarding domperidone use and cardiac risk, the recommendations in the health care advisories would likely be classified as weak. As an example, consider that any recommendation of the American College of Chest Physicians based on this type of evidence would likely be a Grade 2C recommendation (i.e., low or very low quality evidence, observational studies, case reports, or case series), according to the guideline committee's criteria. ${ }^{20}$

Relative to other QTc-prolonging agents associated with similar health care advisory warnings, the level of evidence 
supporting the risk of SCD with domperidone use is slightly weaker. For example, the antidepressants citalopram, escitalopram, and doxepin each have at least one randomized, doubleblind study demonstrating a dose-dependent increase in the QTc interval. ${ }^{21}$ However, most of the evidence supporting the risk of QTc prolongation is comparable to the findings for domperidone, consisting mainly of observational studies (case-control and cohort studies, case reports, and case series). ${ }^{21}$ Similarly, for the antipsychotics haloperidol and ziprasidone, at least one randomized controlled study supports the link between use of these drugs and QTc prolongation; however, most of the evidence for QTc prolongation and antipsychotic use is observational and hence of lower quality. ${ }^{21}$

The clinical importance of the degree of QTc prolongation also remains unknown. Neither of the 2 major epidemiological studies ${ }^{9,10}$ reported the QTc intervals of patients with SCD or of controls. The literature for antidepressants and antipsychotics has reported mean increases in QTc interval of no more than $20 \mathrm{~ms}$, with almost no patients experiencing QTc intervals longer than $450 \mathrm{~ms} .{ }^{21}$ Clinical importance is not easily extrapolated from the literature, as it is largely determined by the individual patient's risk factors. For example, the clinical importance of a QTc interval of $495 \mathrm{~ms}$ in a patient with 3 or 4 QTc-prolonging risk factors is likely to be interpreted with greater caution than the clinical importance of the same QTc interval in a patient with no risk factors (other than the drug in question).

The literature search for the current study yielded no randomized controlled trials or observational studies directly examining the efficacy and safety of domperidone for gastroparesis among patients with end-stage renal disease. Whether there is an increased risk of SCD at higher doses in these patients remains uncertain. In vitro data have suggested a concentrationdependent prolongation of the QTc interval, which in turn suggests a potential dose-response relationship. ${ }^{19}$ Conversely, domperidone is eliminated mostly hepatically, with less than $1 \%$ renal excretion of unchanged drug. ${ }^{22}$ Therefore, this drug does not significantly accumulate in patients with renal impairment. In the absence of literature that is directly applicable to the dialysis population, it is reasonable to obtain guidance from the best available evidence for the general population, with consideration of the additional risk factors for SCD due to dialysis itself.

The low-quality evidence and observational nature of the available literature reflect the ethical obligations surrounding study design and the outcome of QTc prolongation or SCD. Although more robust evidence is required to conclude definitively that domperidone increases the risk of SCD in the general population, a randomized controlled study may not be ethical or practical because most patients using domperidone for diabetes-related gastroparesis are already at higher risk of QTc prolongation. Furthermore, the risk for dialysis patients is 2.5-fold greater, making this understudied population even less eligible for future rigorous studies. The best available evidence must be carefully applied to individual patients, and in each case, the benefits of using domperidone must be weighed against the risks of QTc prolongation in the presence of other risk factors.

\section{CONCLUSIONS AND EXPERT OPINION}

Although the data supporting caution for patients taking more than $30 \mathrm{mg}$ domperidone per day are not strong, it is important to seriously consider this dose limit for high-risk patients. For patients with additional risk factors for QTc prolongation who obtain symptomatic benefit from domperidone use for gastroparesis, periodic electrocardiography (at baseline, 1 month after initiation of the drug, and every 6-12 months thereafter) may be of value. It is the authors' opinion that domperidone should be avoided for patients without symptomatic benefit and those with prolonged QTc interval (> $500 \mathrm{~ms})$ at baseline, with the caveat that this value for the QTc interval is an arbitrary threshold that has not been rigorously proven in the literature.

Overall, the clinical evidence for SCD secondary to domperidone is inconclusive, likely because of the multifactorial etiology of QTc prolongation and SCD. Current regulatory recommendations are based on observational epidemiological studies that generated a signal of increased risk of SCD associated with domperidone use. It appears that this potential risk may be dose-related. In conclusion, given existing gaps in the literature, domperidone use for patients with end-stage renal disease who are undergoing dialysis should be assessed on a case-by-case basis.

\section{References}

1. Whitman IR, Feldman HI, Deo R. CKD and sudden cardiac death: epidemiology, mechanisms, and therapeutic approaches. J Am Soc Nephrol. 2012;23(12):1929-39.

2. Bignotto LH, Kallás ME, Djouki RJT, Sassaki MM, Voss GO, Soto CL, et al. Electrographic findings in chronic hemodialysis patients. J Bras Nefrol. 2012;34(3):235-42.

3. Centers for Disease Control and Prevention. Incidence of end-stage renal disease attributed to diabetes among persons with diagnosed diabetesUnited States and Puerto Rico, 1996-2007. MMWR Morb Mortal Wkly Rep. 2010;59(42):1361-6.

4. Alam U, Asghar O, Malik RA. Diabetic gastroparesis: therapeutic options. Diabetes Ther. 2010;1(1):32-43.

5. Hejazi RA, McCallum RW, Sarosiek I. Prokinetics in diabetic gastroparesis. Curr Gastroenterol Rep. 2012;14(4):297-305.

6. Domperidone maleate - association with serious abnormal heart rhythms and sudden death (cardiac arrest) - for health professionals. Ottawa (ON): Health Canada; 2012 Mar 2 [cited 2014 Sep 28]. Available from: www.healthycanadians.gc.ca/recall-alert-rappel-avis/hc-sc/2012/15857 a-eng.php

7. European Medicines Association, Pharmacovigilance Working Party. Annex 3: Domperidone - risk of cardiac disorders. In: Report of October 2011 plenary meeting. London (UK): European Medicines Association; 2011 Oct 27 [cited 2014 Sep 28]. p. 10-11. Available from: www.ema.europa.eu/ docs/en_GB/document_library/Report/2011/10/WC500117061.pdf

8. Safety alerts for human medical products: domperidone. Food and Drug Administration (US); 2004 [updated 2013 Aug 21; cited 2014 Sep 28]. Available from: www.fda.gov/Safety/MedWatch/SafetyInformation/Safety AlertsforHumanMedicalProducts/ucm 154914.htm 
9. Noord CV, Dieleman JP, van Herpen G, Verhamme K, Sturkenboom MC. Domperidone and ventricular arrhythmia or sudden cardiac death: a population-based case-control study in the Netherlands. Drug Saf. 2010; 33(11):1003-14.

10. Johannes CB, Varas-Lorenzo C, McQuay LJ, Midkiff KD, Fife D. Risk of serious ventricular arrhythmia and sudden cardiac death in a cohort of users of domperidone: a nested case-control study. Pharmacoepidemiol Drug Saf. 2010;19(9):881-8

11. Jolly K, Gammage MD, Cheng KK, Bradburn P, Banting MV, Langman MJ. Sudden death in patients receiving drugs tending to prolong the QT interval. Br J Clin Pharmacol. 2009;68(5):743-51.

12. Straus SM, Sturkenboom MC, Bleumink GS, Dieleman JP, van der Lei J, de Graeff PA, et al. Non-cardiac QTc-prolonging drugs and the risk of sudden cardiac death. Eur Heart J. 2005;26(19):2007-12.

13. Rocha CM, Barbosa MM. QT interval prolongation associated with the oral use of domperidone in an infant. Pediatr Cardiol. 2005;26(5):720-3.

14. Djeddi D, Kongolo G, Lefaix C, Mounard J, Léké A. Effect of domperidone on QT interval in neonates. J Pediatr. 2008;153(5):663-6.

15. Digby G, Machaalany J, Malik P, Methot M, Simpson CS, Redfearn D, et al. Multifactorial QT interval prolongation. Cardiol J. 2010;17(2):184-8.

16. Bruera E, Villamayor R, Roca E, Barugel M, Tronge J, Chacon R. Q-T interval prolongation and ventricular fibrillation with i.v. domperidone. Cancer Treat Rep. 1986;70(4):545-6.

17. Osborne RJ, Slevin ML, Hunter RW, Hamer J. Cardiac arrhythmias during cytotoxic chemotherapy: role of domperidone. Hum Toxicol. 1985;4(6):617-26.

18. Rossi M, Giorgi G. Domperidone and long QT syndrome. Curr Drug Saf. 2010;5(3):257-62.

19. Claassen S, Zünkler BJ. Comparison of the effects of metoclopramide and domperidone on HERG channels. Pharmacology. 2005;74(1):31-6.

20. Guyatt G, Gutterman D, Baumann MH, Addrizzo-Harris D, Hylek EM, Phillips B, et al. Grading strength of recommendations and quality of evidence in clinical guidelines: report from an American College of Chest Physicians task force. Chest 2006;129(1):174-81.
21. Hasnain M, Vieweg WVR. QTc interval prolongation and torsade de pointes associated with second-generation antipsychotics and antidepressants: a comprehensive review. CNS Drugs. 2014;28(10):887-920.

22. Domperidone maleate [product information]. In: Compendium of pharmaceuticals and specialties [electronic version]. Ottawa (ON): Canadian Pharmacists Association; 2012.

Joy Makari, BScPhm, PharmD, was, during the research and writing phases of this manuscript, a candidate for the Doctor of Pharmacy program at the Leslie Dan Faculty of Pharmacy, University of Toronto, Toronto, Ontario. She is now practising as a Clinical Pharmacist in acute care at Sunnybrook Health Sciences Centre, Toronto, Ontario.

Karen Cameron, BScPhm, is Education Coordinator with the University Health Network, Toronto, Ontario.

Marisa Battistella, BScPhm, PharmD, ACPR, is a Clinical Pharmacist with the Hemodialysis Unit of the Toronto General Hospital, University Health Network, and a Pharmacy Clinician Scientist and Assistant Professor with the Leslie Dan Faculty of Pharmacy, University of Toronto, Toronto, Ontario.

Competing interests: None declared.

Address correspondence to:

Dr Marisa Battistella

Pharmacy Department

Toronto General Hospital

200 Elizabeth Street, EB 214

Toronto ON M5G 2C4

e-mail: marisa.battistella@uhn.ca

\section{CJHP Subscriptions 2015 / Abonnements au JCPH 2015}

New for 2015 we have moved to an online only version of CJHP and have also introduced the institutional online subscription option. CJHP online is included as a benefit of CSHP membership. All prices are in Canadian funds.

En nouveauté pour 2015, nous avons migré vers la publication d'une seule version du JCPH, soit la copie électronique en ligne, et nous offrirons aussi en option un abonnement institutionnel. L'abonnement à la version électronique du JCPH publiée en ligne est inclus dans les droits d'inscription à la $\mathrm{SCPH}$. Tous les prix sont en dollars canadiens.

\begin{tabular}{lll}
$\begin{array}{l}\text { Subscriber group / } \\
\text { Groupe d'abonnés }\end{array}$ & $\begin{array}{l}\text { Individual Online Subscription / } \\
\text { Abonnement individuel en ligne }\end{array}$ & $\begin{array}{l}\text { NEW Institutional Online Subscriptions / } \\
\text { NOUVEL abonnement institutionnel en ligne }\end{array}$ \\
\hline $\begin{array}{l}\text { Nonmembers within Canada / } \\
\text { Non-membres au Canada }\end{array}$ & $\begin{array}{l}\$ 160.00 \text { per year, plus GST or HST } \\
160,00 \$ \text { par an, plus TPS ou TVH }\end{array}$ & $\begin{array}{l}\$ 480.00 \text { per year, plus GST or HST } \\
480,00 \$ \text { par an, plus TPS ou TVH }\end{array}$ \\
\hline USA / É.-U. & $\$ 190.00$ per year & $\$ 510.00$ per year \\
& $190,00 \$$ par an & $510,00 \$$ par an \\
\hline Foreign / Étranger & $\$ 230.00$ per year & $\$ 550.00$ per year \\
& $230,00 \$$ par an & $550,00 \$$ par an
\end{tabular}

More details can be found at www.cjhp-online.ca. Please direct any comments or questions cjhpedit@cshp.ca.

Des détails supplémentaires sont fournis à www.cjhp-online.ca. Vous pouvez l'obtenir en visitant le site Web du $J C P H$. Pour tout commentaire ou toute question, veuillez vous adresser à cjhpedit@cshp.ca. 